$$
\begin{aligned}
& \text { Uluslararası Sosyal ve Eğitim Bilimleri Dergisi } \\
& \text { International Journal of Social and Educational Sciences } \\
& \text { Cilt 7, Sayı 14, Aralık } 2020 \text { \& Vol 7, No 14, December } 2020 \\
& \text { (C)2020 Telif Hakkı IJOSES'e aittir }
\end{aligned}
$$

DOI: 10.20860/ijoses. 797472

http://dergipark.gov.tr/ijoses

http://www.ijoses.com

Geliş Tarihi \& Received: 20.09.2020

Kabul Tarihi \& Accepted: 17.11.2020

IJOSES, 2020, 7(14): 233-247

\title{
Sekizinci Sınıf Öğrencilerinin Basit Görsel ve Cebirsel İfadeler Konusundaki Hata ve Kavram Yanılgılarının İncelenmesi*
}

Investigation of the Preservice Science Teachers' Views and Suggestions on the Application of the Cooperative Learning Model in Distance Education Environments

\section{Osman Birgin $^{* *}$ \& Kayhan Demirören ${ }^{* * *}$}

\section{$\ddot{O} \mathbf{z}$}

$\mathrm{Bu}$ araştırmanın amacı, 8. sınıf öğrencilerinin görsel ve cebirsel ifadeler konusundaki hata ve kavram yanılgılarını incelemektir. Çalışma gurubunu Afyonkarahisar ilinde sekizinci sınıfta öğrenim gören 120 ortaokul öğrencisi oluşturmaktadır. Veriler basit görsel ve şekil örüntülerini cebirsel ifade etmeyi gerektiren biri çoktan seçmeli 4'ü açık uçlu sorudan oluşan cebir testi ile toplanmıştır. Veriler betimsel ve içerik analizi yapılarak analiz edilmiştir. Araştırma sonucunda cebir geometri ilişkisini kuramayan öğrencilerin cebirsel ifadeleri anlamakta zorlandıkları ve örüntüden cebirsel denkleme geçemedikleri tespit edilmiştir. Ayrıca öğrencilerin basit görsel ve cebirsel ifadelerdeki hataların yanlış cebirsel işlem seçimi, cebirsel ifadelerde parantezi dikkate almama, şekil örüntüsünü yanlış yorumlama ve aritmetik işlem hatasından kaynaklandığı görülmüştür. Aritmetikten cebire geçişi kolaylaştırmak amaciyla cebir öğretiminde somut materyallerden ve görsellerden daha çok yararlanılması önerilir.

Anahtar Kelimeler: 8. Sınıf, Cebir, Görsel ve Cebirsel İfadeler, Hata, Kavram Yanılgısı,.

\begin{abstract}
The aim of this study is to examine the errors and misconceptions of 8th-grade students on visual and algebraic expressions. The study group consists of 120 middle school students studying in the eighth grade in Afyonkarahisar province. Data were collected with an algebra test consisting of multiple-choice and four written answers question that require an algebraic expression of simple visual and shape patterns. Data were analyzed with descriptive and content analysis. As a result of the research, it was determined that students who could not establish a relationship between algebra and geometric shape had difficulty in understanding algebraic expressions and could not transit from the pattern to the algebraic equation. In addition, it was observed that the errors in simple visual and algebraic expressions of the students were caused by incorrect algebraic operation selection, ignoring parentheses in algebraic expressions, misinterpreting the shape pattern, and arithmetic operation error. In order to facilitate the transition from arithmetic to algebra, it is recommended to use more perceptible materials and visuals in algebra teaching.
\end{abstract}

Keywords: 8th Grade, Algebra, Visual and Algebraic Expressions, Error, Misconception

\footnotetext{
* Bu çalışma, 26-28 Eylül 2019 tarihlerinde İzmir Çeşme'de düzenlenen 4.Uluslararası Türk Bilgisayar ve Matematik Eğitimi Sempoyumunda sunulan sözlü bildirinin genişletimiş hali olup, ikinci yazarın yüksek lisans tezinden üretilmiştir.

** (Prof. Dr.); Uşak Üniversitesi, osman.birgin@usak.edu.tr, ORCID: 0000-0003-3460-2731

*** (Öğretmen); Şemsettin Karahisari Ortaokulu, kayhan-d@ hotmail.com, ORCID: 0000-0001-8862-289
}

Kaynak Gösterme: Birgin Osman, Kayhan D,. " Sekizinci Sınıf Öğrencilerinin Basit Görsel ve Cebirsel İfadeler Konusundaki Hata ve Kavram Yanılgılarının İncelenmesi ". Uluslararası Sosyal ve Eğitim Bilimleri Dergisi 7 (2020 ): 233-247. 


\section{Extended Summary}

\section{Purpose and Significance}

Algebra is one of the important subjects in mathematics. While numerals and numbers are the basis of arithmetic, the basis of algebra is variables that are expressed by letters and symbols. Variables, which are expressed with the help of abstract letters and symbols, provides a significant contribution to algebraic thinking, reasoning, and problem-solving (Akkan, 2009; Linchevski, 1995). The concept of variable also constitutes the basis for abstraction and learning advanced mathematical topics and concepts. In this context, many studies (Blanton \& Kaput, 2003; Cai \& Knuth, 2011; Kieran, 1992; Linchevski, 1995; Perso, 1992) state that algebra is an important subject for students, and the ability of algebraic thinking should be developed as early as possible.

When the literature is examined, it has been shown in many studies conducted at different grade levels that students have a variety of errors in the usage and meaning of the letters in algebraic expressions (Akkaya \& Durmuş, 2006; Bayar, 2007; Baysal, 2010; Carraher \& Schliemann, 2007; Erdem, 2013; Ertekin, 2002; Kieran, 1992; Linchevski, 1995; Perso, 1992; Yenilmez \& Avcu, 2009), and they have misconceptions, and they have difficulties in transitioning from arithmetic to algebra (Akkan \& Baki, 2016; Akkan et al., 2012; Birgin \& Demirören, 2020; Cai \& Knuth, 2011; Gülpek, 2006; Kaya, 2017; Kieran \& Chalouh, 1993; Linchevski \& Herscovics, 1996). In their study conducted with 6-8th grade students, Akkaya and Durmuş (2006) have found that the students had difficulty in perceiving the letters in algebraic representation; they have perceived the letters used in algebraic representation as a numerical position as in the alphabetical order; they perceive letters as digit values and think that letters cannot take any other value than numbers; students do not take into account the order of operations when using letter expressions and parentheses while making transactions; they perceive letters as labels for words.

In recent years, visual shapes and patterns are used in the teaching of algebraic expressions in order to provide the transition from arithmetic to algebra in the first stage of primary education. In the mathematics curriculum (MEB, 2018) updated in 2018 in Turkey, students' acquaintance with algebra starts with patterns in the sixth grade, and students are asked to express patterns by making sense of algebraic expressions. Addition and subtraction in algebraic expressions, the concept of equality, the ability to solve equations with a first-order unknown, for the seventh-grade students, and identities, linear equations, inequalities, factorization, and linear relationships for eighth-grade students are the algebraic achievements. Students who have a lack of knowledge and misconceptions in their pre-sixth grade arithmetic knowledge can carry them to the field of algebra, and misconceptions in algebra negatively affect their subsequent learning. For this reason, it is very important to detect, prevent, and eliminate the misconceptions that occur with the transition to algebra in secondary school, which is the basis of abstract thinking. The aim of this study is to examine the 8th-grade students' errors and misconceptions on simple visual and algebraic expressions.

\section{Methodology}

Participants consists of 120 8th grade students (53.3\% female, $46.6 \%$ male) randomly selected from Afyonkarahisar province. There are 64 (53.3\%) female and 56 (46.6\%) male. An algebra test consisting of one multiple choice and 4 questions requiring written answers was used as a data collection tool. Some studies in the literature (Akkan \& Baki, 2016; Akkaya \& Durmuş, 2006; Herscovics \& Linchevski, 1994; Gülpek, 2006; Linchevski, 1995; Perso, 1992; Yenilmez \&Avcu, 2009), mathematics textbooks, and supplementary books were used in the process of developing the algebra test. The gain of "Understanding simple algebraic expressions and writing in different ways" in the 2018 Middle Grade Mathematics Curriculum was taken as a basis in the development of the algebra test. The opinions of 2 experts and 3 mathematics teachers were taken for the content validity of the draft questions and their suitability to the student level. The answers given by the students to the questions were analyzed according to the descriptive content analysis technique. The answers given by the students to each question were coded as "blank", "wrong or missing answer," and "correct answer". The errors or misconceptions made by the students were created and presented 
descriptively by analyzing the content of the wrong or incomplete answers for each question, codes, and themes. It was determined that the coder compliance percentages calculated for each question were between $83 \%$ and $97 \%$, and the average compliance percentage was $92 \%$.

\section{Results and Recommendations}

In this study, $42.5 \%$ of the students gave correct answers to Question 1, 77.5\% to Question 2, and 33.3\% to Question 4 in explaining the meaning of simple visual and algebraic expressions, and $26.7 \%$ answered Question 5a, and 13.3\% answered Question 3 correctly in the context of the ability to transit from pattern to equation. While the best performance of the students (77.5\%) was in Question 2, which requires the algebraic expression of the perimeter of the hexagon, which one side was given as $(a+2)$, the lowest performance was in Question 3 (13.3\%), which requires the shape pattern and the general rule to be expressed algebraically, and Question 5a (26.7\%) which was given with the number pattern and the general rule was asked.

This study showed that students who could not establish the algebra-geometry relationship had difficulty in understanding algebraic expressions and could not transit from pattern to an algebraic expression. In addition, the errors made by the students in simple visual and algebraic expressions were classified as errors in the selection of algebraic operations, ignoring the parenthesis in the algebraic expression, interpreting the shape pattern incorrectly, and making arithmetic operation errors in the algebraic equations. Among the reasons for this, it can be shown that the traditional instructional approaches on algebraic expressions, which is one-way and based on certain patterns, is preferred more. As a matter of fact, it is stated that more operations, rules, and formulas are memorized, operative and algorithm-based learning is encouraged in algebra teaching in Turkey (Akkan, 2010), and this prevents conceptual learning in algebra and the transition from arithmetic to algebra (Akkan \& Baki, 2016; Bağdat \& Saban, 2014; Gülpek, 2006; Palabıyık \&İspir, 2011, Perso, 1992; Soylu, 2008), and students have many errors and misconceptions about algebraic expressions (Akkaya \& Durmuş, 2006; Akkan et al., 2012; Cai \& Knuth, 2011; Gülpek, 2006; Kieran \& Chalouh, 1993; Linchevski, 1995; Linchevski \& Herscovics, 1996), Yenilmez \& Avcu, 2009). Although it is known that patterns are used in the transition of students to algebraic thinking, it is thought that visual expressions left behind and teachers benefit more from number patterns. In this context, it was determined that although some of the students found the relationships between numbers, they could not establish the algebra-geometry connection in the questions involving geometric shapes. In addition, it was determined that some students made errors due to their geometry knowledge. This situation proves the negative effects of misconceptions on previous topics in the next stages.

This study indicated that students had difficulty in interpreting the algebraic expressions presented in visual form in this study. When the errors made in the study were examined, it was found that the students had the most errors in misconceptions while establishing the algebra-geometry relationship, and the least errors in computation. It is thought that this is due to the fact that the transition from arithmetic to algebra in algebra teaching, which started in the sixth grade, was not reached at the desired levels. In this context, in order to facilitate the transition from arithmetic to algebra, it is recommended to make more use of perceptible materials and visuals in algebra teaching. 


\section{Giriş}

Günlük hayatın ve bilimsel gelişmelerin vazgeçilmez bir unsuru olan matematik, çoğu öğrenci için korkulan ve öğrenilmesi zor bir ders olarak görülmektedir. Çeşitli nedenlerle matematikte başarısız olan öğrenciler bu dersten uzaklaşmakta ve olumsuz tutum sergilemektedirler. Matematik dersindeki başarısızlığın nedenleri arasında öğretim sürecindeki eksik öğrenmeler ve kavram yanılgıları önemli rol oynamaktadır (Baki, 2008). Kavram yanılgısı öğrenciyi sistemli olarak hataya götüren bir kavrayış biçimi olup, öğrencinin yapmış olduğu hata ve yanlışların arka planında çoğu zaman kavram yanılgıları bulunmaktadır (Bingölbali ve Özmantar, 2010). Ancak öğrencinin yapmış olduğu işlem hatası ile kavram yanılgısı arasında önemli bir fark vardır. Hata, genellikle öğrencinin aritmetik işlem ve problem çözme sürecinde dikkatsizlik ya da farkında olmadan yapılan bir işlem hatasını ve yanlışı ifade ederken, kavram yanılgısı öğrencinin yaptığı hatanın ve yanlışın sistematik olmasını, öne sürdüğü eksik ve hatalı kavrayışın doğru olduğunu inanmasını ve gerekçesini açıklayabilmesini ifade etmektedir. Zamanında tespit edilemeyen ve giderilmeyen hata ve kavram yanılgılarının konular ilerledikçe artarak devam etmesi ve öğrenci için anlama zorluklarına yol açması muhtemeldir. $\mathrm{Bu}$ nedenle kavram yanılgılarının tespiti ve giderilmesi matematik eğitimi açısından oldukça önemlidir.

Matematikte soyut konu ve kavramlar arttıkça kavram yanılgıları da artmaktadır. Soyut konuların başında ise cebir gelmektedir. Cebir, örüntülerin, kuralların ve sembollerin bir dilidir (Akkaya ve Durmuş, 2006). Cebir konularının matematik derslerinde öğretilmeye başlamasıyla birlikte öğrencilerin denklem, eşitlik, değişken, cebirsel ifadeler, bilinmeyen gibi cebir kavramlarını anlamakta zorluk yaşadıkları, bazı öğrencilerin ise ezbere yöneldikleri ve konuyu anlamadan cebirsel işlemleri yaptıkları vurgulanmaktadır (Dede ve Argün, 2003; Kieran, 1992; MacGregor ve Stacey, 1994). Baki’ye (2008) göre Türk eğitim sisteminde karşılaşılan temel problemlerden biri kavramsal öğrenmeden ziyade ezbere dayalı öğrenmenin baskın olmasıdır. Ezbere öğrenilen bilgiler ise kısa bir zaman diliminde unutulmakta ve daha sonraki öğrenmeler için zorluk oluşturmaktadır. Bu bağlamda öğrencilere soyut matematiksel bilgileri ezberletmek yerine sağlam cebirsel bir altyapı sağlanması gerektiği ifade edilebilir.

Matematikte genellikle " $a, b, c, m, x, y, z, \ldots$ " gibi harfli ifadeler ile ",$+ \div, \leq,=, \ldots$, gibi matematiksel işlemleri belirten semboller kullanılmaktadır. Aritmetiğin temelinde rakamlar ve sayılar yer alırken, cebirin temelinde harf ve sembollerle ifade edilen değişkenler yer almaktadır. Bu matematiksel sembol ve harfler ile ifade edilen değişkenler problem çözme sürecinde niceliklere dayalı uzun ve zaman alıcı hesaplamalar yapmak yerine matematik problemleri üzerinde soyutlama yaparak daha kolay çözüme ulaşma firsatı sunmaktadır (Akkan ve Baki, 2016; Dede ve Argün, 2003). Üstelik soyut ve simgesel harf ve semboller yardımıyla ifade edilen değişkenler aritmetikten cebire geçişte, cebirsel düşünme ve akıl yürütmede önemli katkı sağlamaktadır (Akkan, 2009; Linchevski, 1995). Değişken kavramı aynı zamanda soyutlama yapma ve ileri matematiksel konu ve kavramların öğrenilmesi için temel oluşturmaktadır. Bu bağlamda birçok araştırma (Blanton ve Kaput, 2003; Cai ve Knuth, 2011; Kieran, 1992; Linchevski, 1995; Perso, 1992) cebirin öğrenciler için önemli bir konu olduğunu ve cebirsel düşünebilmenin mümkün olduğunca erken yaşlarda geliştirilmesi gerektiğini ifade etmektedir. Nitekim alanyazındaki bazı araştırmalar (Akkaya ve Durmuş, 2006; Akkan ve Baki, 2016; Akyüz ve Hangül, 2013; Carraher ve Schliemann, 2007; Kieran ve Chalouh, 1993; Linchevski ve Herscovics, 1996; Macgregor ve Stacey, 1997; Soylu, 2008; Yenilmez ve Avcu, 2009) cebir öncesi ve aritmetikten cebire geçiş dönemine odaklanmıştır. Akkan ve Baki (2016) yapmış oldukları çalışmada 5-8.sınıf öğrencilerinin aritmetikten cebire geçiş süreçlerini sembollerin kullanımı ve harflerin anlamını yorumlama bağlamında incelemişlerdir. Araştırmada sonucunda farklı sınıf düzeyindeki ortaokul öğrencilerinin sınıf düzeyi arttıkça cebirsel sembollerin kullanımı ve harflerin anlamı açısından aritmetikten cebire geçişin olumlu yönde değiştiği ve geliştiği, ancak sınıf düzeyleri arasındaki bu değişim ve gelişim çok az olduğu belirlemişlerdir.

Alanyazın incelendiğinde farklı sınıf seviyelerinde yürütülen birçok araştırmada öğrencilerin cebirsel ifadeler konusunda harflerin kullanımı ve anlamı konusunda çeşitli hatalar yaptıklarını ve kavram yanılgısına sahip olduklarını (Akkaya ve Durmuş, 2006; Bayar, 2007; Baysal, 2010; Carraher ve Schliemann, 2007; 
Erdem, 2013; Ertekin, 2002; Kieran, 1992; Linchevski, 1995; Perso, 1992; Yenilmez ve Avcu, 2009), aritmetikten cebire geçişte zorluk yaşadıklarını (Akkan ve Baki, 2016; Akkan ve diğ., 2012; Birgin ve Demirören, 2020; Cai ve Knuth, 2011; Gülpek, 2006; Kaya, 2017; Kieran ve Chalouh, 1993; Linchevski ve Herscovics, 1996) göstermektedir. Kuchemann (1981) tarafından yapılan çalışmada öğrencilerin cebirsel ifadelerdeki harfli semboller ile ilgili anlamaları altı kategoride sınıflandırmıştır. Bunlar "cebirsel ifadelerdeki harfe tek bir saylsal değer atama", "harfi önemsememe veya yorumlamama", "harfi somut bir nesnenin kısaltması ya da harf olarak düşünme", "harf belirli bir bilinmeyen olarak algılama ve harfe değer vermeksizin, üzerinde çeşitli işlemler yürütme", "harfi genelleştirilmiş bir sayı olarak yorumlayıp birden fazla sayının temsili olarak algılama", "harfi, bir değişken olarak yorumlama" şeklindedir (Akt: Akkan ve Baki, 2016). Benzer şekilde Macgregor ve Stacey (1997) tarafından yapılan çalışmada da 11 ve 12 yaş grubundaki öğrencilerin cebirsel ifadelerdeki harflerle ilgili kavramsal anlamaları "harflerin varlığını önemsememe", "sayısal değer", "bilinmeyen miktar", "kelimelerin kisaltılması", "alfabetik değer" ve "farklı harflerin kullanımı" şeklinde altı tema altında sınıflanmıştır. Üstelik bazı öğrencilerin özellikle her bilinmeyen için farklı harf kullandıkları ve harfe alfabetik sıralamadaki değerini verdikleri saptanmıștır. Akkaya ve Durmuş (2006) tarafından ortaokul öğrencileri (6-8.sınıf) ile yapılan çalışmada öğrencilerin cebirsel gösterimdeki harfleri algılamada zorlandıkları, öğrencilerin cebirsel gösterimde kullanılan harfleri alfabetik sıralamada olduğu gibi harflerin sayısal bir konum belirttiği, harfleri basamak değerleri olarak algıladıkları ve harflerin rakamlardan başka değer alamayacaklarını düşündükleri, öğrencilerin harfli ifadeleri kullanırken işlem sırasını ve işlem yaparken parantezi dikkate almadıkları ve harfleri kelimeler için bir etiket olarak algıladıkları tespit edilmiştir. Erdem (2013), yedinci sınıf öğrencilerinin denklemler konusundaki kavram yanılgılarını belirlediği çalışmasında ise öğrencilerin değişkenler arası kat ilişkini oluşturamama, negatif katsayıyı görmezden gelme, eşitliğin bir tarafindan diğer tarafina terimi işaret değiştirmeden geçirme, işlem önceliğine dikkat etmeden soldan sağa doğru işlem yapma gibi çeşitli eksik öğrenme ve kavram yanılgılarına sahip olduklarını belirlemiştir. Şimşek ve Soylu (2018) tarafindan cebirsel ifadeler konusunda yedinci sınıf öğrencilerinin yaptıkları hataların nedenlerinin incelendiği çalışmada öğrencilerin cebirsel ifadeler konusundaki bilgilerinin istenilen düzeyde olmadığı ve birçok hata yaptıkları saptanmıştır. Yapılan bu hatalar arasında öğrencinin değişkeni görmezden gelmesi, verilen cebirsel ifadeyi denkleme dönüştürerek çözmesi, soruda verilen değişken yerine $x$ değişkenini kullanması ve verilen probleme uygun denklemi yanlış kurması yer almaktadır. Çakmak Gürel ve Okur (2018) tarafindan yedinci ve sekizinci sınıf öğrencileri ile yapılan çalışmada eşitlik ve denklem konusundaki öğrencilerin en fazla değişkenlerin birbirinden her zaman farklı olarak algılanması, en az ise cebirde parantezlerin dikkate alınmaması şeklinde kavram yanılgısına sahip oldukları belirlenmiştir. Ayrıca yedinci sınıf öğrencilerinin sekizinci sınıf öğrencilerinden daha fazla kavram yanılgısına sahip oldukları tespit edilmiştir. Erbaş, Çetinkaya ve Ersoy (2009) tarafından lise öğrencileri ile yapılan çalışmada öğrencilerin en sık yaptıkları hatalar arasında cebirsel anlamda parantezi dikkate almama, matematikte işlemleri her zaman soldan sağa doğru yapma, eşitliğin bir tarafinda yapılan işlemin tersini diğer tarafta yapma, ters işlemleri gereksiz olarak görme ve çıkarma işleminde değişme özelliğini kullanma olduğu saptanmıştır. Diğer taraftan Akkan, Baki ve Çakıroğlu (2012) tarafından 5-8. sınıf öğrencileri ile yapılan çalışmada öğrencilerin aritmetikten cebire geçiş sürecinde problem çözümlerindeki değişim ve gelişimleri incelenmiştir. Cebirsel çözümlerde 5. sınıf öğrencileri genellikle geometrik şekilleri kullanırken, 7. sınıf ve 8. sınıf öğrencileri genellikle $x$ ve $y$ değişkenlerini tercih ettikleri, öğrenim düzeyi artıkça problem çözme açısından aritmetikten cebire geçişim olumlu yönde geliştiği, ancak farklı sınıf düzeylerinde bu değişimin çok az olduğu saptanmıştır. En belirgin değişimin ise 7. sınıf ile 8. sınıf ögrencileri arasında olduğu belirlenmiştir. Yenilmez ve Avcu'nun (2009) altıncı sınıf öğrencilerinin cebir öğrenme alanındaki başarı düzeylerini inceledikleri çalışmada öğrencilerin eşitliğin gösterimi ve korunumu sorularında problem yaşamadıkları, ancak denklem kurma ve kurulan denklemi çözme konusunda zorluk çektikleri saptanmıştır.

Son yıllarda ilköğretimin ilk kademesinde aritmetikten cebirsel geçişin sağlanabilmesi için cebirsel ifadelerin öğretiminde görsel şekil ve örüntülerden yararlanılmaktadır. Ülkemizde 2018 yılında güncellenen matematik öğretim programında öğrencilerin cebirle tanışmaları altıncı sınıf seviyesinde örüntüler ile başlamakta, öğrencilerden cebirsel ifadeleri anlamlandırarak, örüntüleri ifade etmeleri istenmektedir. 
Yedinci sınıf seviyesinde öğrencilerin cebirsel ifadelerde toplama ve çıkarma, eşitlik kavramı, birinci dereceden bir bilinmeyenli denklemleri çözebilmeleri, sekizinci sınıfta ise özdeşlikler, doğrusal denklemler, eşitsizlikler, çarpanlara ayırma ve doğrusal ilişkiler ile cebir kazanımları yer almaktadır (MEB, 2018). Altıncı sınıf öncesi aritmetik bilgilerinde bilgi eksikliği ve kavram yanılgıları olan öğrencilerin bunları cebir alanına taşıyabilmekte, cebirde oluşan kavram yanılgıları da sonraki öğrenmeleri olumsuz olarak etkilemektedir. Bu nedenle soyut düşünmenin temelinin atıldığ1 ortaokul dönemimde cebire geçişle birlikte oluşan kavram yanılgılarının tespiti, önlenmesi ve ortadan kaldırılması oldukça önemlidir. Bu araştırmanın amacı, sekizinci sınıf öğrencilerinin basit görsel ve cebirsel ifadeler konusundaki hata ve kavram yanılgılarını incelemektir.

\section{Yöntem}

$\mathrm{Bu}$ araştırmada betimsel tarama modelinden yararlanılmıştır. Betimsel tarama modelinde araştırılacak olan konu, birey, nesne kendi koşulları içinde olduğu gibi betimlenmeye ve açıklanmaya çalışılır. Bu yönüyle geçmişte ya da halen var olan bir durumu olduğu gibi betimlemeyi amaçlayan araştırmalar için oldukça uygundur (Karasar, 2000). Ortaokul sekizinci sınıf öğrencilerinin basit görsel ve cebirsel ifadeler konusundaki hata ve kavram yanılgılarının incelendiği bu araştırma, betimsel tarama niteliğindedir.

\section{Çalışma Grubu}

Bu araştırmanın çalışma grubunu, 2017-2018 eğitim-öğretim yılında Afyonkarahisar il merkezi, ilçe ve beldelerinde öğrenim gören, amaçlı örnekleme ile belirlenen 64'ü (\%53.3) kız ve 56'sı (\%46.7) erkek olmak üzere toplam 120 öğrenci oluşturmaktadır. Araştırmaya gönüllü olarak katılmak isteyen öğrenciler dahil edilmiştir.

\section{Veri Toplama Aracı}

Veriler yedi alt bölümden ve toplam 30 sorudan oluşan "Cebir testi" yardımıyla toplanmıştır. Cebir testinin pilot çalışması 100 sekizinci sınıf öğrenci üzerinde gerçekleştirilmiş olup geçerlik ve güvenirlik çalışmaları yapılmıştır. Cebir testinde yer alan maddelerin ayırt ediciliğinin 0.30 'dan yüksek olduğu, madde güçlüğü değerleri bakımından test içerisinde hem zor hem kolay hem de orta düzeyde sorular olduğu belirlenmiştir. Cebir testinin KR-20 güvenirlik katsayısı 0.90 olarak hesaplanmıştır. Bu araştırma kapsamında sadece cebir testinin içinde yer alan biri çoktan seçmeli, 4'ü yazılı cevap gerektiren 5 sorudan oluşan "Basit görsel ve cebirsel ifadelerin anlamını açıklama, örüntüden denkleme geçebilme" boyutuna ait veriler yansıtılmaktadır. Soruların geliştirilmesi sürecinde alan yazındaki çalışmalardan (Akkan ve Baki, 2016; Akkaya ve Durmuş, 2006; Herscovics ve Linchevski, 1994; Gülpek, 2006; Linchevski, 1995; Perso, 1992; Yenilmez ve Avcu, 2009), matematik ders kitapları ve yardımcı kitaplardan yararlanılmıştır. Soruların geliştirilmesinde 2018 Matematik Öğretim Programında (MEB, 2018) yer alan "Basit cebirsel ifadeleri anlama ve farkl biçimlerde yazma" kazanımı temel alınmıştır. Sorular, basit görsel ve şekil örüntülerini cebirsel olarak ifade etmeyi gerektirmektedir. Taslak soruların içeriği ve öğrenci düzeyine uygunluğu için 2 alan uzmanın ve 3 matematik öğretmenin görüşü alınmıştır. Alınan görüşler doğrultusunda bazı soruların ifadelerinde ve görsellerinde düzenleme yapılmış, bir soru görüşler doğrultusunda ölçme aracından çıkarılmıştır. Bu çalışma kapsamında kullanılan sorular bulgular bölümünde yer almaktadır.

\section{Verilerin Analizi}

$\mathrm{Bu}$ araştırma kapsamında öğrencilerin sorulara verdikleri cevaplar betimsel içerik analizi tekniğine göre çözümlenmiştir. Betimsel analiz tekniği, çeşitli veri toplama araçlarıyla elde edilen ham verilerin daha önceden belirlenen temalara göre özetlenmesini ve yorumlanmasını gerektiren nitel veri analiz türüdür. Bu analiz türünde elde edilen bulguların okuyucuya anlaş1lır bir biçimde sunulması ve doğrudan alıntılara sık sık yer verilmesi önemlidir (Yıldırım ve Şimşek, 2005). Bu nedenle çalışma kapsamında öncelikle öğrencilerin her bir soruya verdikleri yanıtlar "boş", "yanlış", "eksik cevap" ve "doğru cevap" olarak kodlanmıştır (Tablo 1). Her bir soruya ilişkin yanlış ya da eksik cevapların içerik analizi yapılarak öğrencilerin yapmış oldukları hata veya kavram yanılgılarına ilişkin kod ve temalar oluşturularak betimsel olarak sunulmuştur. Yazılı cevap gerektiren soruların kodlama güvenirliği için rastgele seçilen 30 öğrencinin 
cevapları başka bir araştırmacı tarafından ayrıca kodlanmıştır. Kodlama güvenirliği için Miles ve Huberman'ın (1994) önerdiği kodlayıcı uyum yüzdesi formülü [Uyum yüzdesi = Görüş Birliği/(Görüş Birliği + Görüş Ayrılı̆̆g)] kullanılmıştır. Her bir soru için hesaplanan kodlayıcı uyum yüzdelerinin \%83-\%97 arasında değer aldığı ve ortalama uyum yüzdesinin \%92 olduğu belirlenmiştir. Bu nedenle elde edilen verilerin araştırma için güvenilir olduğu kabul edilmiştir.

Tablo 1. Öğrenci yanıtlarının analizinde kullanılan kodlama tablosu

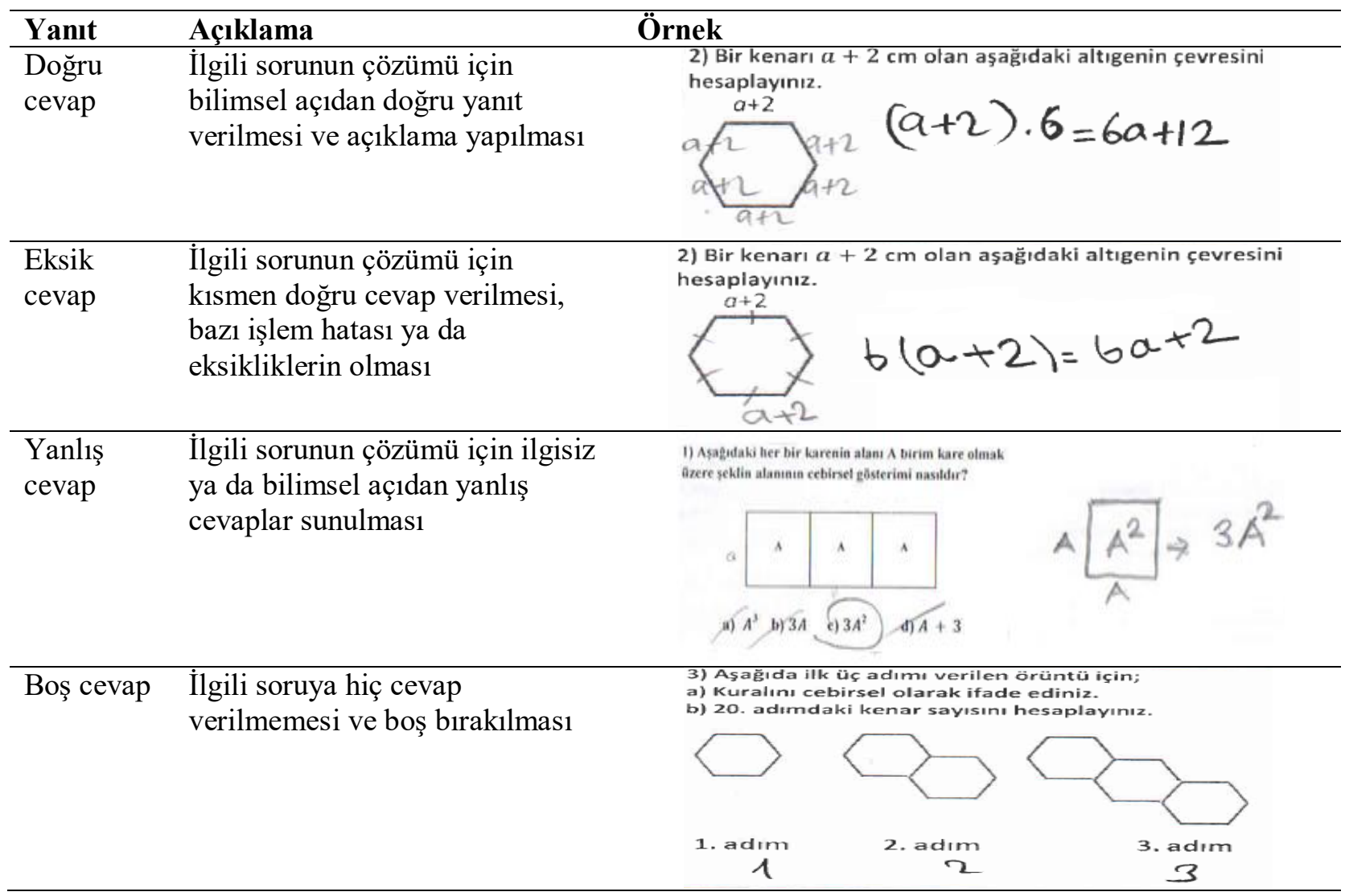

\section{Bulgular}

$\mathrm{Bu}$ çalışma kapsamında sekizinci sınıf öğrencilerinin basit görsel ve cebirsel ifadelerin anlamını açıklama ve örüntüden denkleme geçebilme becerisine ilişkin sorulara verilen cevapların frekans ve yüzdelik dağılımı Tablo 2'de sunulmuştur.

Tablo 2. Basit görsel ve cebirsel ifadelerin anlamını açıklama ve örüntüden denkleme geçebilme becerisine ilişkin yüzdelik dăğlım $(n=120)$

\begin{tabular}{lccc}
\hline Soru No & Doğru Cevap & Yanlıș / Eksik Cevap & Boş \\
\hline Soru 1 & $51(\% 42.5)$ & $65(\% 54.2)$ & $4(\% 3.3)$ \\
Soru 2 & $93(\% 77.5)$ & $21(\% 17.5)$ & $6(\% 5.0)$ \\
Soru 3 & $16(\% 13.3)$ & $41(\% 34.2)$ & $63(\% 52.5)$ \\
Soru 4 & $40(\% 33.3)$ & $45(\% 37.5)$ & $35(\% 29.2)$ \\
Soru 5a & $32(\% 26.7)$ & $46(\% 38.3)$ & $42(\% 35.0)$ \\
Soru 5b & $65(\% 54.2)$ & $27(\% 22.5)$ & $28(\% 23.3)$ \\
\hline
\end{tabular}


Tablo 2 incelendiğinde basit görsel ve cebirsel ifadelerin anlamını açıklamada bağlamında öğrencilerin \%42.5'i Soru 1'i, \%77.5'i Soru 2'yi ve \%33.3'ü Soru 4'ü doğru cevaplayabildikleri, örüntüden denkleme geçebilme bağlamında ise öğrencilerin \%26.7'i Soru 5a'y1 ve \%13.3'ü Soru 3'ü doğru cevap verebilmişlerdir. Bu bağlamda öğrencilerin en yüksek başarı performansını (\%77.5) bir kenarı $(a+2)$ olarak verilen altıgenin çevre uzunluğunun cebirsel olarak ifade edilmesi olan Soru 2'de iken, en düşük başarı performansını ise şekil örüntüsü verilen ve genel kuralının cebirsel olarak ifade edilmesini gerektiren Soru 3 (\%13.3) ile say1 örüntüsü verilen ve genel kuralı istenen Soru 5a (\%26.7) olmuştur. Bu yönüyle düşünüldüğünde öğrencilerin görsel içeren sorularda cebir geometri ilişkisini tam olarak kuramadıkları ve aritmetik bilgilerini cebirsel bilgiler ile birleştirmekte zorlandıkları tespit edilmiştir. Ayrıca birçok öğrencinin görsel ve sayı örüntülerini cebirsel olarak ifade etmeyi gerektiren sorularda daha çok zorlandıkları ve hata yaptıkları belirlenmiştir.

Öğrencilerin basit görsel ve cebirsel ifadelerin anlamını açıklama, örüntüden denkleme geçebilme kazanımı ile ilgili hatalarının frekansları, kavram yanılgı türleri ve örnek cevaplar Tablo 3'de sunulmuştur.

Tablo 3. Basit görsel ve cebirsel ifadelerin anlamını açıklama ve örüntüden denkleme geçebilme bağlamındaki hata ve kavram yanılgıları

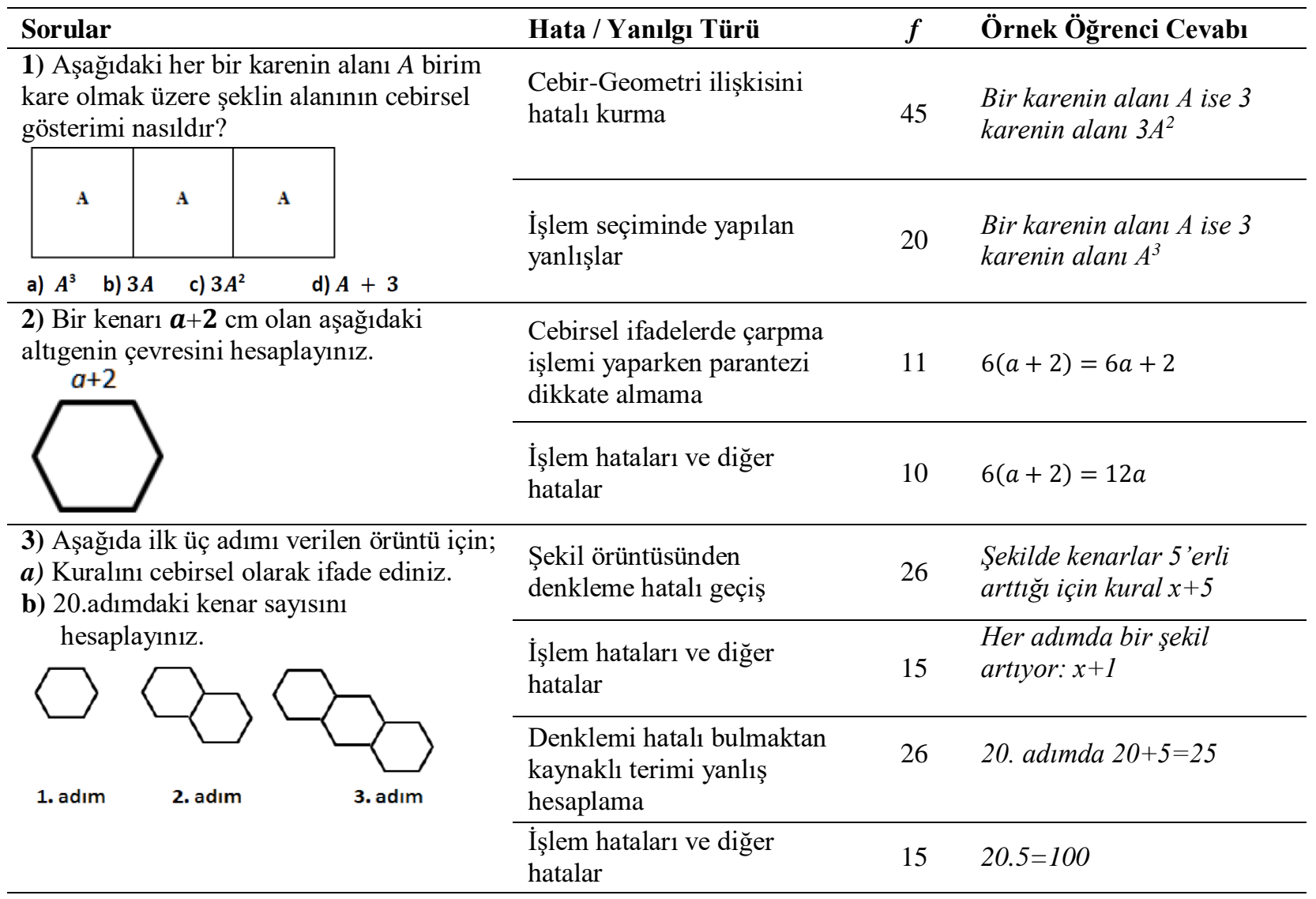


4) İki eş dikdörtgen ve bir eşkenar üçgenden oluşan aşağıdaki şekilde; dikdörtgenin kısa kenarı ' $a$ ' ve uzun kenarı ' $b$ ' olduğuna göre şeklin çevresini cebirsel olarak ifade ediniz.

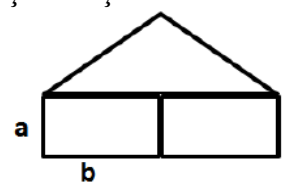

Cebir-Geometri ilişkisini hatalı kurma
45

Şekilde tüm kenarların

toplamı çevredir; $8 b+2 a$
5) $3,7,11,15,19, \ldots$ şeklinde ilerleyen bir dizinin;

a) Kuralını cebirsel olarak ifade ediniz.

b) 20. terimini bulunuz.

\begin{tabular}{lcl}
$\begin{array}{l}\text { Örüntüden denkleme hatalı } \\
\text { geçiş }\end{array}$ & 27 & $\begin{array}{l}\text { 4'er artan dizi: } x+4 \\
\text { 4'lü gidiyor: } 4 x\end{array}$ \\
\hline İşlem hataları ve diğer hatalar & 19 & 20.terim $=23$ \\
\hline $\begin{array}{l}\text { Denklemi hatalı bulmaktan } \\
\text { kaynaklı terimi yanlış } \\
\text { hesaplama }\end{array}$ & 27 & $\begin{array}{l}x+4 \text { için 20. terim: } 24 \\
\text { 4x için 20. terim: } 80\end{array}$ \\
\hline
\end{tabular}

Tablo 3'de görüldüğü gibi öğrencilerin bu kazanımda 5 tür hata ve kavram yanılgısına sahip oldukları belirlenmiştir. Öğrencilerin sahip oldukları hata ve yanılgı türlerine ilişkin örnek açıklamalar detaylı olarak aşağıda sunulmuştur:

a) Cebir-Geometri İlişkisini Hatalı Kurma: Öğrencilerde bu yanılg1 türü geometrik şekillerin boyutlarının değişkenlerle ifade edildiği Soru $1(\% 37.5)$ ve Soru 4'te $(\% 37.5)$ ortaya çıkmıştır. Soru 1'de karelerin alanları ' $A$ ' ile ifade edilmesine rağmen bunu bir kenar olarak düşünen öğrenciler bir karenin alanını ' $\mathrm{A}^{2}$ ', üç karenin alanını ise ' $3 \mathrm{~A}^{2}$ ' olarak ifade etmişlerdir. Soru 4'te ise kapalı bir şeklin çevresi sorulduğunda yalnızca dışta kalan kenarları toplamak yerine şeklin içindeki ve dışında kalan tüm kenarları toplayıp şeklin çevresini ‘ $8 b+2 a$ ' olarak ifade etmişlerdir (Şekil 1). Bu durum bazı öğrencilerin bir geometrik şeklin çevresi ve alanı konusundaki sahip oldukları bilgileri aşırı genellediklerini ve kavram yanılgısına sahip olduklarını işaret etmektedir.

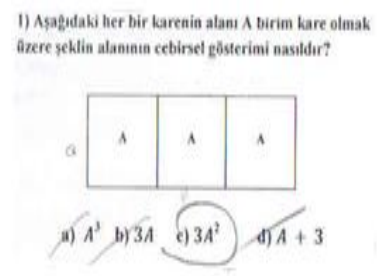

(Ö34’ün cevab1)

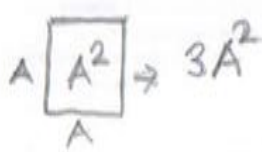

Şekil 1. Cebir-geometri ilişkisini hatalı kurmaya ilişkin bazı örnekler

b) İşlem Seçiminde Yapılan Hata ve Yanılgılar: Öğrencilerin matematik problemleri çözerken sıkça yaptıkları hatalardan olan işlem seçimi yanılgısı Soru 1'de (\%16.7); 'Bir karenin alanı 'A' ise 3 karenin alanı $A^{3}$ ' tür.' şeklinde ortaya çıkmıştır (Şekil 2). Bu durum bazı öğrencilerin bir tam sayı ile cebirsel ifadelerin çarpma işleminde, üslü ifade ile çarpma işleminin etkisini ayırt etmede kavram yanılgısına sahip olduğunu göstermiştir. 


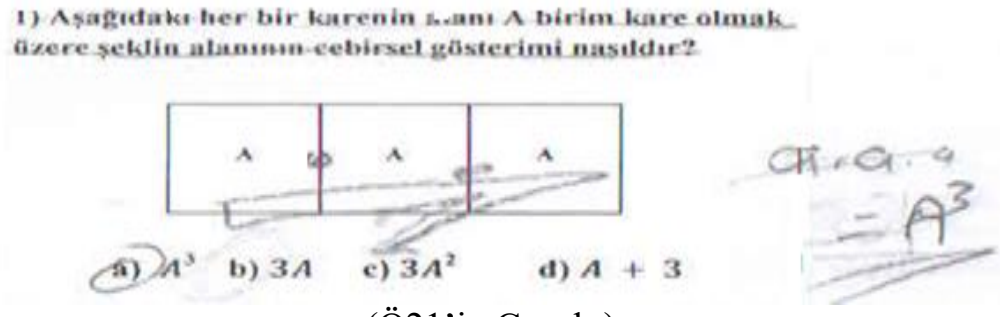

(Ö21'in Cevab1)

Şekil 1. İşlem seçiminde yapılan hata örnĕgi

c) Cebirsel İfadelerde Çarpma İşlemi Yaparken Parantezi Dikkate Almama: Öğrenciler bu tür cebirsel hata Soru 2'de ortaya çıkmıştır. Soru 2'de bazı öğrenciler (\%9.2) bir kenarı $(a+2)$ olarak verilen altıgenin çevresi için $6(a+2)$ işleminde parantezi dikkate almadan yaptıkları, sadece parantez içindeki ilk terim olan ' $a$ ' ile 6 sayısını çarparak altıgenin çevresini $6 a+2$ şeklinde ifade ettikleri belirlenmiştir (Şekil 3). Bu durum bazı öğrencilerin cebirsel ifadelerde çarpma işleminde parantezin etkisini göz ardı ettiklerini ve dikkate almadıklarını göstermektedir.

2) Bir kenan $a+2 \mathrm{~cm}$ olan aşağıdaki altıgenin çevresini hesaplayınız.
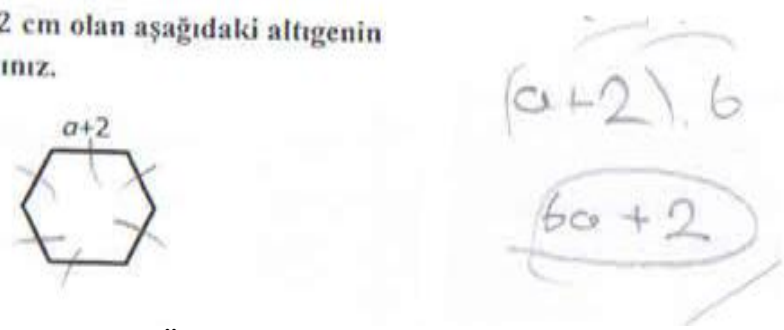

(Ö30'in Cevab1)

Şekil 2. Işslem seçiminde yaptıkları hata örneğ $i$

d) Şekil Örüntüsünden Denkleme Hatalı Geçiş: Soru 3a'da bazı öğrenciler (\%21.7) şekil örüntüsünün kuralını belirlerken kenarların 5'er arttığını tespit etmişler; ancak bunu cebirsel olarak ifade ederken ' $x+5$ ' şeklinde yazmışlardır (Şekil 4). Benzer şekilde 27 öğrenci (\%22.5) Soru 5a'da sayı örüntüsünden denkleme hatalı geçiş yaptıkları belirlenmiştir. Sayı dizisindeki 4'erli artışı fark eden bu ögrenciler sayı dizisinin genel kuralını ' $x+4$ ' ya da ' $4 x$ ' şeklinde ifade ederek yanılgıya düşmüşlerdir (Şekil 4). Bu kavram yanılgısı, öğrencilerin bir sayı ve şekil örüntüsünde artış değerini değişken ile doğrudan toplama ya da çarpma işlemi olarak ifade etmelerinden kaynaklanmaktadır. Bu durum bazı öğrencilerin şekil örüntülerinden cebirsel ifadeye geçişte bilgi eksikliği ve kısıtlı algılamaya sahip olduklarını göstermektedir.

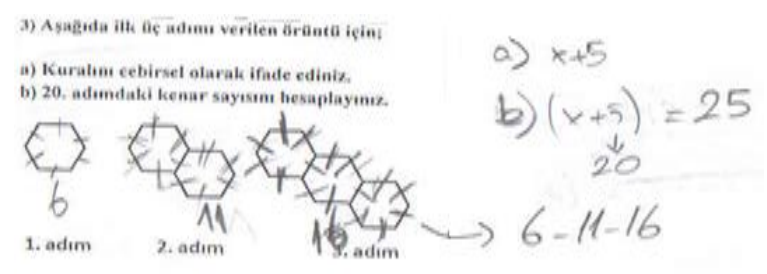

(Ö18'in Cevab1)

\section{5) $3,7,11,15,19 \ldots$ seklinde ilerleyen bir dizinin}

a) Kuralım cebirsel olarak ifade ediniz

(Ö35'in Cevab1)

Şekil 3. Şekil örüntüsünden denkleme geçişte hata örnekleri 
e) Denklemi Hatalı Bulmaktan Kaynaklı Terimi Yanlış Hesaplama: Soru 3a ile bağlantılı olarak verilen şekil örüntüsünde genel kuralı (cebirsel denklemi) yanlış ifade eden 26 öğrenci (\%22.7) Soru 3b'de şekil örüntüsünün 20.terimini ' $x+5$ ' için ' $20+5=25$ ' şeklinde hatalı hesaplamışlardır (Şekil 5). Benzer şekilde Soru 5b'de verilen sayı dizisinde 27 ögrenci (\%22.5) sayı dizisinin genel kural hatasından kaynaklı 20. terimi ' $x+4$ ' için ' 24 ', ' $4 x$ ' için ' 80 ' olarak hatalı ifade etmiştir (Şekil 5). Bu sorularda bazı öğrencilerin istenen şekil örüntüsünün ve sayı dizisinin 20.terimi sayarak buldukları belirlenmiştir. Bu durum öğrencilerin basit görsel ifadeleri cebirsel olarak ifade etmede zorluk yaşadıklarını göstermektedir.

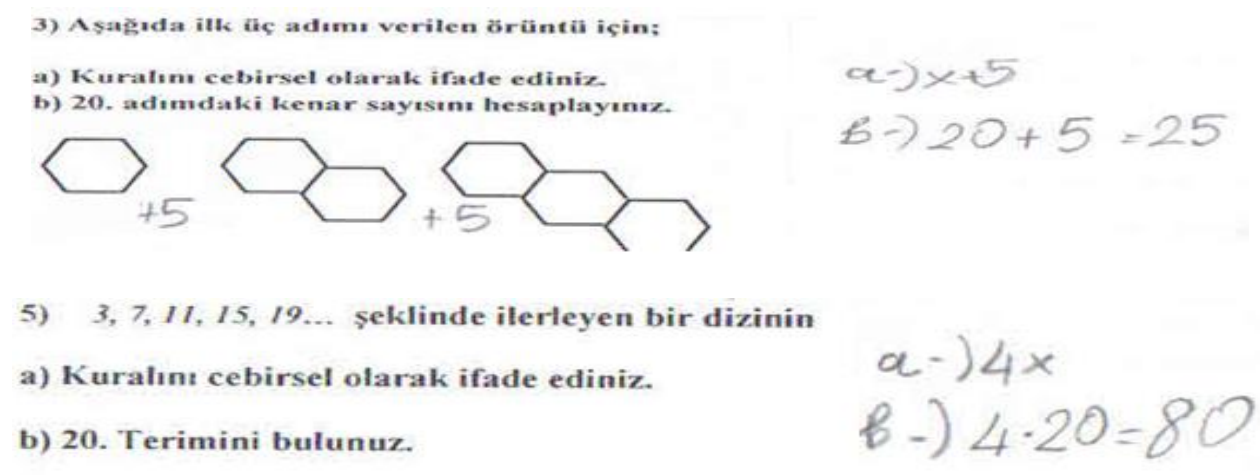

(Ö76’nın Cevabı)

Şekil 4. Denklem hatasından kaynaklı terimi yanlış hesaplama örnekleri

Tartışma ve Sonuç

Bu araştırma kapsamında birçok sekizinci sınıf öğrencisinin basit görsel ve cebirsel ifadeleri anlamını açıklamada ve birbiri arasındaki geçiş yapmada çeşitli hata ve kavram yanılgılarının olduğu tespit edilmiştir. Öğrencilerin basit görsel ve cebirsel ifadelerin anlamını açıklama ile örüntüden denkleme geçebilme konusunda "Cebir-geometri ilişkisini hatalı kurma", "Hatalı işlem seçimi", "Cebirsel ifadelerde çarpma işleminde parantezi dikkate almama", "Şekil örüntüsünden denkleme hatalı geçiş", "Denklemi hatalı bulmaktan kaynakl terimi yanlış hesaplama" şeklinde hata ve kavram yanılgılarına sahip oldukları belirlenmiştir. $\mathrm{Bu}$ araştırmada cebir-geometri ilişkisini hatalı kuran öğrencilerin cebirsel ifadelerin anlamlarını ifade etmekte zorlandıkları ve örüntüden denkleme geçişte başarılı olamayan öğrencilerin de istenen terimi bulamadıkları belirlenmiştir. Bu durum matematik derslerinde daha çok cebirsel ifadeler konusunda aritmetik işlem boyutunun ön plana çıkarıldı̆̆ 1 , görsel ve cebirsel ifadelerin farklı gösterim türleri arasında geçişlere yeterince yer verilmediği şeklinde yorumlanabilir. Nitekim yapılan bazı araştırmalar (Akkaya ve Durmuş, 2006; Birgin ve Demirören, 2020; Macgregor ve Stacey, 1997; Perso, 1992) öğrencilerin daha çok görsel ifade içeren cebirsel problemlerde daha başarısız olduklarını ortaya koymaktadır. Bu yönüyle bu araştırmanın bulgularını destekler niteliktedir.

$\mathrm{Bu}$ araştırmada basit görsel ve cebirsel ifadelerde cebir-geometri ilişkisini kuramayan bazı ögrenciler 1.soruda karelerin alanları ' $A$ ' ile ifade edilmesine rağmen bunu bir kenar olarak düşünerek bir karenin alanını; ' $A$ ', 3 karenin alanını ise ' $3 A^{2}$ ' olarak ifade etmişlerdir. Benzer şekilde 4 . soruda kapalı bir şeklin çevresi sorulduğunda yalnızca dışta kalan kenarları toplamak yerine gördükleri tüm kenarları toplayarak çevreyi ifade etmişlerdir. Şekil örüntüsünden denkleme hatalı geçişte ise öğrencilerin bir kısmı Soru 3a'da şekil örüntüsünün kuralını belirlerken kenarların 5'erli arttıklarını tespit etmişler; ancak bunu cebirsel olarak hatalı ifade etmişlerdir. Soru 5a'da ise sayı örüntüsünden denkleme hatalı geçiş gözlenmiştir. Sayılardaki 4'erli artış1 gören öğrenciler kuralı ' $x+4$ ' ya da ' $4 x$ ' şeklinde düşünmüşlerdir. Bunun nedeni olarak öğrencilerin bir artış gördüklerinde doğrudan toplama ya da çarpma işlemine yöneldikleri düşünülmektedir. Alanyazın incelendiğinde öğrencilerin cebir-geometri ilişkisi kurmada ve şekil örüntüsünden cebirsel denkleme geçişte zorlandıkları ve yanlış genellemeler yaptıkları belirlenmiştir (Akkaya ve Durmuş, 2006; 
Bağdat ve Saban, 2014; Gülpek, 2006; Palabıyık ve İspir, 2011, Perso, 1992). Kabael ve Tanışlı (2010) tarafından değişik öğretim kademelerinde şekil örüntüleri bağlamında yapılan çalışmada kibrit çöpleri ile oluşturulan bir örüntünün genel formülünü değişken yardımıyla doğru ifade etmeleri beklenmesine karşın birçok öğrencinin genel terimi doğru yazmakta zorlandıkları tespit edilmiştir. Ayrıca denklemlerdeki hatalardan kaynaklı soruların yanlış çözüldüğünü bazı çalışmalar dikkat çekmektedir (Çakmak Gürel ve Okur, 2018; Erbaş, Çetinkaya ve Ersoy, 2009; Ertekin, 2002; Kieran, 1992; Kösa, 2004). Benzer şekilde Özarslan (2010) yapmış olduğu çalışmasında bazı yedinci sınıf öğrencilerin denklemi hatalı kurmaktan kaynaklı sorulara yanlış cevaplar verdiklerini saptamıştır. Bu bağlamda bu çalışmanın bulgularıyla benzerlik gösterdiği ifade edilebilir.

$\mathrm{Bu}$ araştırmada basit görsel ve cebirsel ifadelerde işlem seçiminde yapılan hatalar incelendiğinde bazı öğrencilerin Soru 1'de olduğu gibi 'Bir karenin alanı 'A' ise 3 karenin alanı $A^{3}$ ' tür.' şeklinde yanılgıya sahip oldukları belirlenmiştir. Tüm alanları toplamak yerine çarparak hatalı sonuçlar elde edilmiştir. Benzer şekilde Soylu (2008) yaptığı çalışmasında " 40 'tan $m$ kadar eksik" ifadesi için hatalı işlem seçimi nedeniyle " $40 . m$ " şeklinde ifade eden öğrenciler olduğunu tespit etmiştir. Alanyazında öğrencilerin buna benzer hatalar yaptıklarını gösteren çeşitli araştırmalar da vardır (Akgün, 2007; Akkan ve diğ., 2012; Çakmak Gürel ve Okur, 2018; Kaya, Keşan, İzgiol ve Erkuş, 2016; Stacey ve MacGregor, 1997; Şimşek ve Soylu, 2018). Bu yönüyle bu araştırmanın bulgularını destekler niteliktedir.

$\mathrm{Bu}$ araştırmada bazı öğrencilerin bir kenarı $(a+2)$ olarak verilen altıgenin çevresi için $6(a+2)$ işleminde parantezi dikkate almadan $6 a+2$ şeklinde ifade ettikleri belirlenmiştir. Bu yönüyle cebirsel ifadelerde çarpma işlemi yaparken parantezi dikkate alınmadığı tespit edilmiştir. Benzer şekilde alanyazın incelendiğinde (Akarsu, 2013; Akkaya ve Durmuş, 2006; Bayar, 2007; Erbaş ve diğ., 2009; Erdem, 2013; Kieran, 1992; Kuchemann, 1981; Macgregor ve Stacey, 1997; Perso, 1992) cebirsel ifadelerde parantezin kullanımı ile ilgili karşılaşılan benzer hata ve kavram yanılgıların sıklıkla karşılaşıldığı görülmektedir. Baysal (2010), 4-8.sınıf öğrencileri ile yapmış olduğu çalışmasında " $m=5 n+1$ ” ifadesinde " $n$ " değerinin 2 artırılması istendiğinde öğrencilerin " $n+2$ " ifadesini parantez kullanarak ifade etmek yerine 5 ile 2 'yi toplayarak çarpma işleminin toplama işlemi üzerine dağılımında parantezi dikkate almadıklarını tespit etmiştir. Çakmak Gürel ve Okur (2018) da yaptıkları çalışmada 7.sınıf düzeyindeki bazı öğrencilerin $6(x+$ 3) şeklindeki cebirsel işlemde parantezi görmezden gelip $6 x+3$ şeklinde işlem yaptıklarını belirlemişlerdir.

$\mathrm{Bu}$ araştırmada sekizinci sınıf öğrencilerinin cebir geometri ilişkisini kurmakta zorlandıkları, şekil örüntüleri ve görsel içeren sorularda hata yaptıkları görülmüştür. Bunun temelinde görsel ve cebirsel ifadelerde cebirsel düşünme becerisinin yeterince gelişmemesinin, aritmetik ve geometrideki bilgi eksikliğinin önemli faktör olduğu söylenebilir. Benzer şekilde yapılan birçok araştırma ortaokul öğrencilerinin aritmetikten cebire geçişte zorluk yaşadıklarını (Akkaya ve Durmuş, 2006; Akkan ve diğ., 2012; Cai \& Knuth, 2011; Gülpek, 2006; Kieran ve Chalouh, 1993; Linchevski, 1995; Linchevski ve Herscovics, 1996), ortaokul düzeyinde sınıf düzeyi artmasına karşın cebirsel düşünme becerilerindeki gelişimin beklenen düzeyde olmadığını (Akkan ve Baki, 2016; Birgin ve Demirören, 2020; Kaya, 2017) ortaya koymaktadır. $\mathrm{Bu}$ nedenle özellikle denklemlere geçişte değişkenlerin sadece belli harflere indirgenmemesi, çeşitli görsellerle ve somut materyaller yardımıyla günlük hayatla ilişkilendirilmesi önerilmektedir. Ayrıca aritmetikten cebire geçişte önemli bir yere sahip olan örüntülerde, sayı örüntüleriyle birlikte şekil örüntülerinin de üzerinde durulmasının öğrenci kavramsal öğrenmesi açısından faydalı olacağı düşünülmektedir. Nitekim Palabıyık ve İspir (2011) yapmış oldukları çalışmada 7.sınıf düzeyinde gerçekleştirilen örüntü temelli cebir öğretimin geleneksel öğretime göre öğrencilerin işlemsel cebir testi performanslarında anlamlı fark oluşturmadığını, ancak öğrencilerin cebirsel düşünme becerileri ve kavramsal öğrenmeleri üzerinde anlamlı fark oluşturduğunu saptamışlardır. Bu bağlamda 2018 Matematik Öğretim Programında (MEB, 2018) vurgulandığ gibi öğrencilerin aritmetikten cebire geçişlerini kolaylaştırmak için cebirsel ifadelerin öğretiminde hem sayı örüntülerinde hem de şekil örüntülerinde yararlanması gerektiği ifade edilebilir. 
$\mathrm{Bu}$ araştırmada sekizinci sınıf öğrencilerinin basit görsel ve cebirsel ifadeler kapsamındaki hata ve kavram yanılgıları incelenmiştir. Bundan sonra yapılacak çalışmalarda cebirsel ifadeler ve denklemlerin çözümünde yapmış oldukları hata ve kavram yanılgıları detaylı olarak incelenebilir.

\section{Kaynakça}

Akarsu, E. (2013). 7. sınıf ögrrencilerinin cebir ögrenme alanında matematiksel dil kullanımlarının incelenmesi (Yayımlanmamış yüksek lisans tezi). Dokuz Eylül Üniversitesi, Eğitim Bilimleri Enstitüsü, İzmir.

Akgün, L. (2007). Değiş̧ken kavramına ilişskin yeterlilikler ve değişken kavramının öğretimi. (Yayınlanmamış doktora tezi). Atatürk Üniversitesi, Fen Bilimleri Enstitüsü, Erzurum.

Akkan, Y. (2009). İlköğretim öğrencilerinin aritmetikten cebire geçiş süreçlerinin incelenmesi (Yayımlanmamış doktora tezi). Karadeniz Teknik Üniversitesi, Fen Bilimleri Enstitüsü, Trabzon.

Akkan, Y. ve Baki, A. (2016). Ortaokul öğrencilerinin aritmetikten cebire geçiş süreçlerinin incelenmesi: Sembollerin kullanımı ve harflerin anlamı. Bayburt Eğitim Fakültesi Dergisi, 11(2), 270-305.

Akkan, Y., Baki, A. ve Çakıroğlu, Ü. (2012). 5-8. sınıf öğrencilerinin aritmetikten cebire geçiş süreçlerinin problem çözme bağlamında incelenmesi. Hacettepe Üniversitesi Eğitim Fakültesi Dergisi, 43, 1-13.

Akkaya, R. ve Durmuş, S. (2006). İlköğretim 6-8. sınıf öğrencilerinin cebir öğrenme alanındaki kavram yanılgıları. Hacettepe Üniversitesi Eğitim Fakültesi Dergisi, 31, 1-12.

Akyüz, G. ve Hangül, T. (2013). 6. sınıf öğrencilerinin denklemler konusunda sahip oldukları yanılgıların giderilmesine yönelik bir çalışma. Kuramsal Eğitimbilim Dergisi, 7(1),16-43.

Bağdat, O. ve Saban, P.(2014). İlköğretim 8. sınıf öğrencilerinin cebirsel düşünme becerilerinin solo taksonomisi ile incelenmesi. International Journal of Social Science, 26, 473-496.

Baki, A. (2008). Kuramdan uygulamaya matematik eğitimi. Ankara: Harf Eğitim Yayıncılık.

Bayar, H. (2007). I. dereceden bir bilinmeyenli denklem konusundaki ögrenci hatalarının analizi (Yayınlanmış yüksek lisans tezi). Balıkesir Üniversitesi Eğitim Bilimleri Enstitüsü, Balıkesir.

Baysal, F. K. (2010). İlköğretim öğrencilerinin (4-8. Sinıf) cebir öğrenme alanında oluşturdukları kavram yanılgıları (Yayınlanmış yüksek lisans tezi). Abant İzzet Baysal Üniversitesi Sosyal Bilimler Enstitüsü, Bolu.

Bingölbali, E. ve Özmantar, M. F. (2010). İlköğretimde karşılaşılan matematiksel zorluklar ve çözüm önerileri (2. bask1). Ankara: Pegem Akademi Yayınevi.

Birgin, O. ve Demirören, K. (2020). Ortaokul yedinci ve sekizinci sınıf öğrencilerinin cebirsel ifadeler konusundaki başarı performanslarının incelenmesi. Pamukkale Üniversitesi Eğitim Fakültesi Dergisi, 50, 99-117.

Blanton, M., \& Kaput, J. (2003). Developing elementary teachers' algebra eyes and ears. Teaching Children Mathematics, 10(2), 70-77.

Cai, J., \& Knuth, E. (2011). Early algebraization. New York: Springer.

Carraher, D. W., \& Schliemann, A. (2007). Early algebra and algebraic reasoning. In F. K. Lester (Ed.), Second handbook of research on mathematics teaching and learning (Vol. 2, pp. 669-705). Reston: NCTM.

Çakmak Gürel, Z., Okur, M. (2018). 7. ve 8. sınıf öğrencilerinin eşitlik ve denklem konusundaki kavram yanılgıları. Cumhuriyet Uluslararası Eğitim Dergisi, 6(4), 479-507. 
Dede, Y. ve Argün, Z. (2003). Cebir, öğrencilere niçin zor gelmektedir? Hacettepe Üniversitesi Eğitim Fakültesi Dergisi, 24, 180-185.

Erbaş, A. K., Çetinkaya, B. ve Ersoy, Y. (2009). Öğrencilerin basit doğrusal denklemlerin çözümünde karşılaştıkları güçlükler ve kavram yanılgıları. Eğitim ve Bilim, 34(152), 45-59.

Erdem, Z. Ç. (2013). Öğrencilerin denklem konusundaki hata ve kavram yanılgılarının belirlenmesi ve bu hata ve yanılgıların nedenleri ve giderilmesine ilişkin ögretmen görüşleri (Yayınlanmış yüksek lisans tezi). Adıyaman Üniversitesi, Fen Bilimleri Enstitüsü, Adıyaman.

Ertekin, E. (2002). Denklemlerin öğretimindeki yanılgıların teşhisi ve sebeplerinin belirlenmesi (Yayınlanmamış yüksek lisans tezi). Selçuk Üniversitesi, Fen Bilimleri Enstitüsü, Konya.

Gülpek, P. (2006). İlköğretim 7. ve 8. sinıf ögrrencilerinin cebirsel düşünme düzeylerinin gelişimi (Yayınlanmamış yüksek lisans tezi). Uludağ Üniversitesi, Bursa.

Herscovics, N., \& Linchevski, L. (1994). A cognitive gap between arithmetic and algebra. Educational studies in mathematics, 27(1), 59-78.

Kabael, T. ve Tanışl1, D. (2010). Cebirsel düşünme sürecinde örüntüden fonksiyona öğretim. İlkögrretim Online, 9(1), 213-228.

Karasar, N. (2000). Bilimsel araştırma yöntemi (10. Baskı). Ankara: Nobel Yayın Dağıtım.

Kaya, D. (2017). Yedinci sınıf öğrencilerinin cebirsel düşünme düzeyleri ile becerilerinin incelenmesi. Bartın Üniversitesi Ĕ̈itim Fakültesi Dergisi, 6(2), 657-675.

Kaya, D., Keşan, C., İzgiol, D. ve Erkuş, Y. (2016). Yedinci sınıf öğrencilerinin cebirsel muhakeme becerilerine yönelik başarı düzeyi. Turkish Journal of Computer and Mathematics Education, 7, 142163.

Kieran, C. (1992). The learning and teaching of school algebra. In Grouws DA (Ed.), Handbook of research on mathematics teaching and learning (pp. 390-419). New York: Macmillan Publishing Company.

Kieran, C., \& Chalouh, L. (1993). Prealgebra: The transition from arithmetic to algebra. In P. S. Wilson (Ed.), Research ideas for the classroom: Middle grades mathematics (pp. 119-139). New York: Macmillan

Kösa, T. (2004). 8. Sinıf ögrrencilerinin sözel problemlerin çözümünde denklemlerden yararlanabilme becerileri (Yayınlanmamış yüksek lisans tezi). Karadeniz Teknik Üniversitesi, Fen Bilimleri Enstitüsü, Trabzon.

Kuchemann, D. (1981). Algebra. In K. Hart (ed.), Children's understanding of mathematics: 11-16 (pp. 102119). London: John Murray.

Linchevski, L. (1995). Algebra with numbers and arithmetic with letters: A definition of pre-algebra. The Journal of Mathematical Behaviour, 14, 113-120.

Linchevski, L., \& Herscovics, N. (1996). Crossing the cognitive gap between arithmetic and algebra: operating on the unknown in the context of equations. Educational Studies in Mathematics, 30, 38-65.

MacGregor, M.\& Stacey, K. (1994). Cognitive models underlying students' formulation of simple linear equations. Journal for Research in Mathematics Education, 24(3), 217-232.

Macgregor, M., \& Stacey, K. (1997). Students' understanding of algebraic notation: 11-15, Educational Studies in Mathematics, 33, 1-19.

MEB (2018). Ortaokul matematik dersi (5-6-7-8. sinıflar) öğretim programı. Ankara: MEB Yayınları.

Miles, M. B., \& Huberman, M. A. (1994). Qualitative analysis: An expanded sourcebook. Thousand Oaks, CA: Sage. 
Özarslan, P. (2010). İlköğretim 7. sını ögrencilerinin cebirsel sözel problemleri denklem kurma yoluyla çözme becerilerinin incelenmesi (Yayınlanmamış yüksek lisans tezi). Çukurova Üniversitesi, Sosyal Bilimleri Enstitüsü, Adana.

Palabıyık, U. ve İspir, O. A. (2011). Örüntü temelli cebir öğretiminin öğrencilerin cebirsel düşünme becerileri ve matematiğe karşı tutumlarına etkisi. Pamukkale Üniversitesi Ĕ̆itim Fakültesi Dergisi, 30(2), 111 123.

Perso, T. (1992). Using diagnostic teaching to overcome misconceptions in algebra. The Mathematical Association of Western Australia (INC), Subiaco W.A.

Soylu, Y. (2008). 7. sınıf öğrencilerinin cebirsel ifadeleri ve harf sembollerini (değişkenleri) yorumlamaları ve bu yorumlamada yapılan hatalar. Ahmet Keleşoğlu Eğitim Fakültesi Dergisi, 23, 237 -248.

Stacey, K., \& MacGregor, M. (1997). Ideas about symbolism that students bring to algebra. The Mathematics Teacher, 90(2), 110-113.

Şimşek, B. ve Soylu, Y. (2018). Ortaokul 7. sınıf öğrencilerinin cebirsel ifadeler konusunda yaptıkları hataların nedenlerinin incelenmesi. Journal of International Social Research, 11(59), 830-848.

Yenilmez, K. ve Avcu, T. (2009). Altıncı sınıf öğrencilerinin cebir öğrenme alanındaki başarı düzeyleri. Ahi Evran Üniversitesi Eğitim Fakültesi Dergisi, 10(2), 37-45.

Yenilmez, K. ve Teke, M. (2008). Yenilenen matematik programının öğrencilerin cebirsel düşünme düzeylerine etkisi. İn̈nü Üniversitesi Eğitim Fakültesi Dergisi, 9(15), 229-246.

Yıldırım, A. ve Şimsek, H. (2005). Sosyal bilimlerde nitel araştırma yöntemleri (5.Baskı). Ankara: Seçkin Yayınlar1. 